\title{
Sequential Use of Fibroblastic Growth Factor 2 and Transforming Growth Factor $\beta 1$ in Cartilage Tissue Engineering Using Canine Chondrocytes
}

\author{
Wanda J. Gordon-Evans ${ }^{1, *}$, Michael J. Yaeger ${ }^{2}$, M. Heather Greenlee ${ }^{3}$ and Michael G. Conzemius ${ }^{4}$
}

${ }^{I}$ Department of Veterinary Clinical Medicine, University of Illinois, Urbana-Champaign. Formerly Department of Biomedical Sciences Iowa State University; ${ }^{2}$ Department of Veterinary Pathology, Iowa State University; ${ }^{3}$ Department of Biomedical Sciences, Iowa State University and ${ }^{4}$ Department of Veterinary Clinical Sciences, University of Minnesota, Twin Cities

\begin{abstract}
This study investigated the effect of fibroblast growth factor 2 in monolayer followed by transforming growth factor $\beta 1$ in 3-dimensional culture on chondrocytic matrix production. Under the culture conditions presented, FGF2 is mitogenic but not chondrogenic. In addition, TGF $\beta 1$ stimulation produced predominantly type I collagen.
\end{abstract}

\section{INTRODUCTION}

Osteoarthritis (OA) is the second leading cause of disability in the United States, and it has been estimated that the disease will affect $18.2 \%$ of the population in the United States by 2020 [1]. Eighty percent of those diagnosed with OA have limited mobility and $25 \%$ cannot perform major daily activities [2]. In addition to modeling OA in research directed towards human applications, canine OA is recognized as a significant problem in veterinary medicine. One in 5 adult dogs is diagnosed with $\mathrm{OA}$, and $62 \%$ of dogs affected show clinical signs of disability $[3,4]$. Recent efforts to improve the quality of life of those afflicted in human and veterinary medicine have focused on joint resurfacing technologies including tissue engineered constructs [5-7].

Growth factors are used commonly in an effort to improve the amount and quality of engineered tissue. However, many growth factors may produce dramatically different results. More specifically, Transforming Growth Factor $\beta 1$ (TGF $\beta 1$ ) and Fibroblastic Growth Factor 2 (FGF2) have produced variable results depending on the culture conditions, species and type of cell used [8-19]. Additionally, the biosynthetic activity may be influenced by sequential or concomitant use of growth factors [17].

FGF2 has been reported to be mitogenic, decrease dedifferentiation of chondrocytes in monolayer, increase the time to senescence, and prime the cells for collagen production in 3-dimensional culture [20-23]. FGF2 can also decrease the production of type II collagen, increase type I collagen production, and decrease the time to hypertrophic differentiation $[10,15,24,25]$.

The effect of TGF $\beta 1$ is also controversial and dependent on culture conditions [26]. TGF $\beta 1$ has demonstrated a negative effect on proteoglycan production when added to me-

*Address correspondence to this author at the Department of Veterinary Clinical Medicine, University of Illinois, Urbana-Champaign. Formerly Department of Biomedical Sciences Iowa State University, USA;

E-mail: wjgevans@uiuc.edu dium containing serum with conflicting results when serumfree medium is used [27,28]. Additionally, TGF $\beta 1$ may increase or decrease type II collagen deposition affecting the biomechanical properties of the engineered cartilage $[10,11$, $24,26]$. The species, cell density, and dose ranges present in the literature likely contribute to the variation in results [26].

Determination of the ideal culture environment for promoting the appropriate extracellular matrix production is important for subsequent in vivo joint resurfacing studies using the canine model. Production on a clinical scale requires predictable, repeatable matrix grown in a relatively short period of time.

The purpose of this study was to determine the effect of FGF2 as a pretreatment in monolayer on chondrocytes as well as the effect of TGF $\beta 1$ on 3-dimensional pellets in culture. The hypothesis was that the chondrocytes pretreated the FGF2 and cultured 3 dimensionally with TGF $\beta 1$, would have the fastest growth with the largest amount and highest quality of matrix produced.

\section{MATERIALS AND METHODS}

Cytokines were purchased from R\&D Systems, Minneapolis, MN. All other components were purchased from Sigma-Aldrich, St. Lois, MO unless otherwise stated.

\section{Chondrocyte Harvest and Proliferation}

Articular cartilage was harvested from the humeral head and the femoral condyle of a small mixed breed adult dog with approval from the Iowa State University Animal Care and Use Committee. The dog's age was estimated between 1 and 3 years and was euthanized for reasons unrelated to this study. Harvested cartilage was immediately placed in Dulbecco's modified eagle medium (DMEM) with $1 \%$ penicillin/streptomycin. The cartilage was diced into $1-2 \mathrm{~mm}$ pieces and placed into type II collagenase in DMEM $(0.5 \mathrm{mg} / \mathrm{ml}$ concentration). The pieces were incubated at $37^{\circ} \mathrm{C}$ and $5 \%$ $\mathrm{CO}_{2}$ for 24 hours. The released cells were pelleted, washed 
with DMEM, and counted. Cells were plated at $0.8 \times 10^{5}$ cells per $25 \mathrm{~cm}^{2}$ culture flask. Culture medium used consisted of DMEM, $10 \%$ fetal bovine serum (FBS), 1\% penicillin/streptomycin. After the first passage, the pellets were replated in $75 \mathrm{~cm}^{2}$ flasks with 300,000 cells and randomized to receive FGF2 at $5 \mathrm{ng} / \mathrm{ml}$ or no additional cytokines [19]. Media was changed 3 times per week. When cells reached about $90 \%$ confluency, they were trypsinized washed and replated within the consistent group.

\section{Pellet Cultures}

Passage 3 chondrocytes were used in 3-dimensional (3D) pellet culture. The cells were trypsinized and counted. Cells were diluted to $1 \times 10^{6}$ cells $/ \mathrm{ml}$ of serum free medium. The cell solution was aliquoted $(0.5 \mathrm{ml})$ to each $15 \mathrm{ml}$ tube. The tubes were centrifuged at $500 \mathrm{~g}$ for 5 minutes and incubated at $37^{\circ} \mathrm{C}$ and $5 \% \mathrm{CO}_{2}$. The serum free medium consisted of DMEM with final concentration of $0.1 \mathrm{mM}$ ascorbic acid, $1.25 \mathrm{mg} / \mathrm{ml} \mathrm{BSA}, 10^{-7} \mathrm{M}$ dexamethasone, $1 \%$ penicillin/ streptomycin, and $1 \mathrm{ml} / \mathrm{ml} \mathrm{ITS}+1 \mathrm{premix}(10 \mathrm{mg} / \mathrm{ml}$ insulin, $5.5 \mathrm{mg} / \mathrm{L}$ transferrin, and $5 \mu \mathrm{g} / \mathrm{ml}$ selenium).

After 2 days in 3-dimensional culture, cytokines were added to the pellets in the appropriate group with 10 pellets per group. Four groups were created for each of the monolayer groups for a total of 8 groups: 1). FGF2 pretreatment and $5 \mathrm{ng} / \mathrm{ml} \mathrm{FGF2}$ in 3-D culture; 2). FGF2 pretreatment and $10 \mathrm{ng} / \mathrm{ml}$ TGF $\beta 1$ in 3-D culture; 3). FGF2 pretreatment and no growth factors in 3-D culture; 4). FGF2 pretreatment and $10 \%$ FBS in 3-D culture; 5). No pretreatment and $5 \mathrm{ng} / \mathrm{ml}$ FGF2 in 3-D culture; 6). No pretreatment and $10 \mathrm{ng} / \mathrm{ml} \mathrm{TGF}$ $\beta 1$ in 3-D culture; 7). No pretreatment and no growth factors in 3-D culture; 8). FGF2 pretreatment and 10\% FBS in 3-D culture [19]. Appropriate medium and growth factor was changed every 3 days for 3 weeks.

\section{Histopathology}

Three of the 10 pellets from each group were processed for histopathology. The pellets were fixed for 24 hours in $10 \%$ neutral buffered formalin. To facilitate handling, the pellets were stained with 50\% hematoxylin, and imbedded in agar base. Agar was heated to $38-40^{\circ} \mathrm{C}$ and was pored over the pellet. The agar-pellet construct was refrigerated for 10 minutes at which time the agar was solid and it was returned to formalin for processing.

The agar-pellet construct was routinely processed and embedded in paraffin. Five micron sections were stained with hematoxylin and eosin for evaluation of cell morphology and safranin $\mathrm{O}$ with fast green counterstain for glycosaminoglycan (GAG) visualization.

In addition to subjective evaluation, the slides were also evaluated using imaging software to determine the percent of tissue stained by Safranin $O$ and the density of viable cells. The cell density was determined by hand marking the cells with clearly defined nuclei and cell borders. Those cells with undefined nuclei and/or marked vacuolization were considered degenerate. The number of cells is then expressed as a ratio to the area of the tissue.

The quantitative analysis was performed using image analysis software (IPLab, Scanalytics, Inc, Rockville, MD).
The area of GAG staining was quantified and expressed as a percent of the total area. The number of viable cells were counted and presented as a ratio to the area of the $\mathrm{H}$ and $\mathrm{E}$ slides.

\section{Capillary Electrophoresis}

The remaining pellets were digested in cyanogen bromide $(\mathrm{CNBr})$ and collagen types I and II were quantitated by capillary electrophoresis using methods similar to those previously described $[29,30]$. Pellets were preserved in a RNA preservation solution (Ambion, Austin, TX) and frozen at $20^{\circ} \mathrm{C}$ until digestion.

At the time of digestion, the pellets were thawed and soaked in PBS overnight at $4{ }^{\circ} \mathrm{C}$ to leach out the preservative. The pellets were then heated in $70 \%$ formic acid at $60^{\circ} \mathrm{C}$ for 1 hour followed by digestion with $5 \% \mathrm{CNBr}$ for 48 hours. Samples were diluted with distilled water to halt the reaction, and freeze dried. The samples were then rehydrated in $1 \mathrm{~mL}$ $1 \%(\mathrm{v} / \mathrm{v})$ acetic acid and heated in a water bath for $60 \mathrm{~min}-$ utes at $60^{\circ} \mathrm{C}$. Samples were then filtered through columns (MacroSpin SEC G-10, The Nest Group, Inc, South Borough, MA). After filtration the sample was transferred to a 2 $\mathrm{mL} \mathrm{CE}$ vial. One $\mu 1$ bradykinin at $1 \mathrm{mg} / \mathrm{mL}$ and $999 \mu \mathrm{l}$ distilled water were added to the sample vial. Bradykinin was used as an internal control with a final concentration of 0.5 $\mu \mathrm{g} / \mathrm{ml}$.

Samples were injected ( 20 seconds at $1 \mathrm{psi}, 177 \mathrm{nl}$ ) into a Beckman Coulter P/ACE MDQ capillary electrophoresis system coupled to a selectable wavelength UV/VIS detector set at $214 \mathrm{~nm}$. A neutral, coated capillary (Microsolv Tech, Eatontown, NJ) was used with a capillary temperature of $20^{\circ} \mathrm{C}$ and sample storage at $4{ }^{\circ} \mathrm{C}$. The capillary was washed with buffer prior to sample injection. Separation was carried out at $25 \mathrm{kv}$ for 60 minutes with normal polarity. The buffer used was $100 \mathrm{mM}$ Sodium Phosphate at $\mathrm{pH}$ 6.0. Type I and II collagen were quantitated using a standard curve. The standard curve was derived using purified type I and type II bovine collagen (Chondrex, Redmond, Wa). The $\mathrm{R}^{2}$ value for the type I and II collagen curves was 0.95 with a mean square error of 0.009 and 0.0001 , respectively. Although the minimum detection limit was not sought, the lowest known amount of collagen used for the standard curve was $0.89 \mathrm{ng}$.

\section{RESULTS}

The cells receiving FGF2 in monolayer took an average 3 days after passage to grow to confluency whereas it took 6 days until the serum only group was confluent. Therefore the cells that were supplemented with FGF2 in monolayer (32 days) allowed completion of the experiment 14 days prior to the group that did not receive the cytokine during monolayer culture (46 days).

In pellet culture, TGF $\beta 1$ had a grossly visible effect on the pellets regardless of pretreatment. (Fig. 1) The effect of TGF $\beta 1$ also was apparent in wet weight. The pellets in both monolayer groups that received FGF2, serum, or no cytokines in pellet culture weighed less than $0.1 \mathrm{mg}$. The group that received serum only in monolayer, but TGF $\beta 1$ in pellet culture had a mean weight $( \pm \mathrm{SE})$ of $2.7 \mathrm{mg}( \pm 0.05)$. Similarly, the group that received FGF2 in monolayer and TGF $\beta 1$ in pellet culture had a mean weight of $2.5 \mathrm{mg}( \pm 0.16)$. 

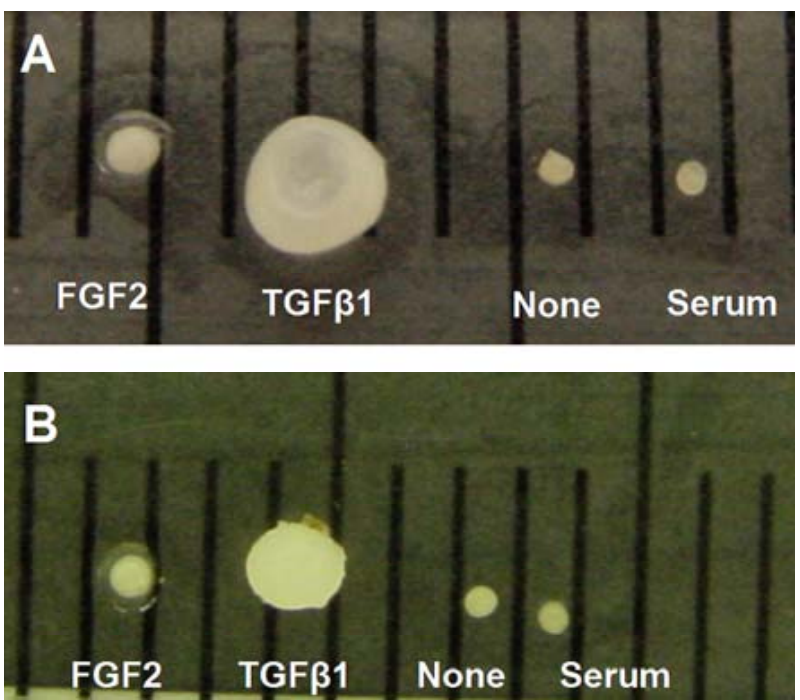

Fig. (1). Gross appearance of pellets after 3 weeks in culture with pellets receiving FGF2 in monolayer A and without pretreatment B. Marks represent $1 \mathrm{~mm}$ spaces. Pellets labeled by 3-dimensional treatment.
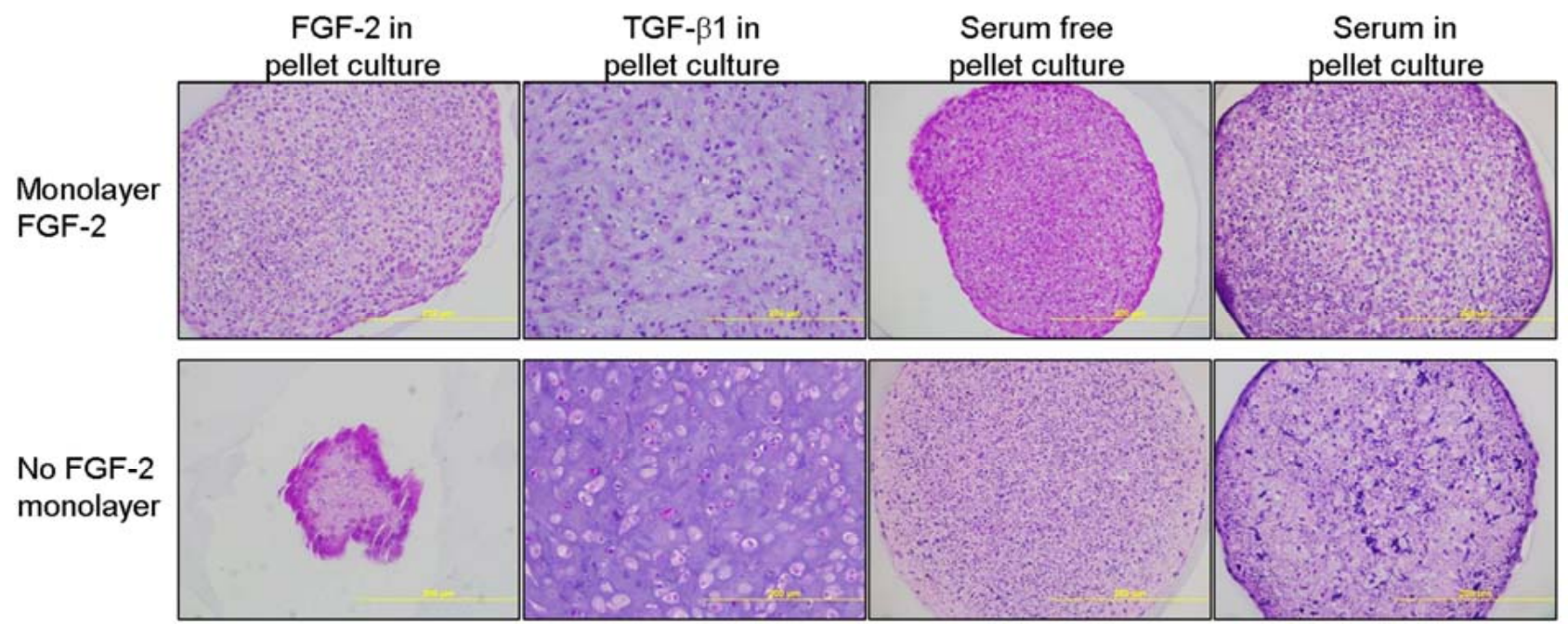

Fig. (2). Chondrocyte pellet histopathology stained with hematoxylin and eosin after 3 weeks in culture. All pictures are at $40 \mathrm{X}$ magnification. Yellow bar represents $200 \mu \mathrm{m}$.
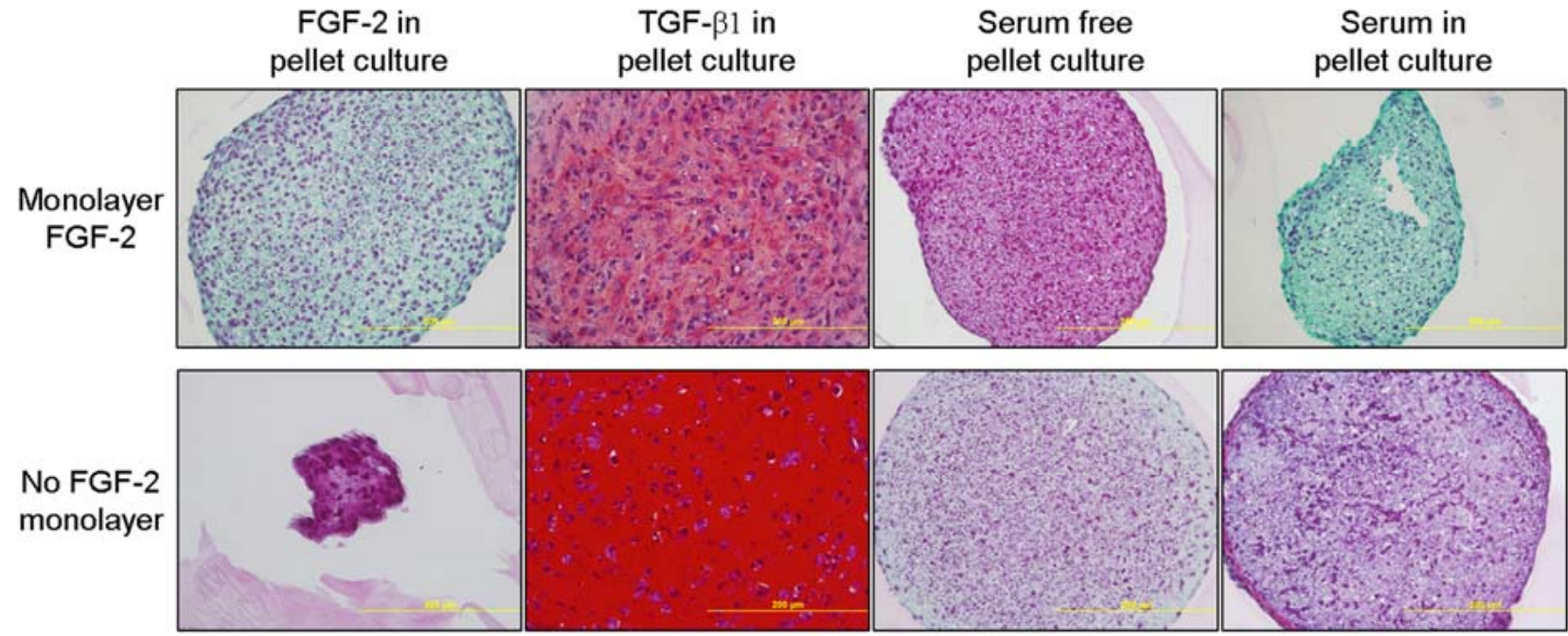

Fig. (3). Chondrocyte pellet histopathology stained with safranin $\mathrm{O}$ and fast green after 3 weeks in culture. All pictures are at $40 \mathrm{X}$ magnification. Yellow bar represents $200 \mu \mathrm{m}$.

\section{Histopathology}

Histopathologic evaluation revealed large differences between groups. (Figs. 2 and 3) $\mathrm{H}$ and $\mathrm{E}$ stained sections showed mature chondrocytes in lacunae sparsely distributed across a dense matrix in the pellets treated with TGF $\beta 1$ without FGF2 pretreatment. This group was the most similar to articular cartilage. The FGF2 pretreated pellets that were also treated with TGF $\beta 1$ showed healthy mature cells in a atrix, but lacunae were not well formed and cells were sub the FGF2 pretreated group had a cell density of 1084 cells $/ \mathrm{mm}^{2}$ compared to 495 cells $/ \mathrm{mm}^{2}$ for the group that did not receive FGF2. The remaining groups did not show the matrix formation or the cellular maturity of the TGF $\beta 1$ treated pellets.

The group treated with FGF2 in both monolayer and 3dimensional culture showed dense cellularity with marked necrocellular debris, degenerate cells evidenced by pyknotic nuclei, and little to no matrix present. The group provided FGF2 in 3 dimensional culture, but not in monolayer showed 
immature cells on the periphery with necrocellular debris centrally. Immature cells were defined by multiple nucleoli, dispersed chromatin and large nuclei. There was not a large difference in the appearance of viable cell population between the groups receiving FGF2 in 3-dimensional culture (3715 cells $/ \mathrm{mm}^{2}$ pretreated and 3070 cells $/ \mathrm{mm}^{2}$ no pretreatment); however the 2 groups receiving FGF2 in 3-D culture each contained the higher number of cells by a factor of 3 over any other groups.

The pellets cultured 3-dimensionally in serum-free media without growth factors showed marked necrosis centrally with a ring of immature cells in the periphery. The group receiving FGF2 in monolayer but no growth factor in 3dimensional culture showed cells with slightly less basophilic staining. The groups receiving serum supplementation while in 3-dimensional culture, showed less debris; however, signs of cell death were prominent. Irregular nuclear and cellular margins and the presence of large vacuoles were considered signs of cell death. The peripheral cells appeared healthy, but immature. Basophilic matrix was more prominent in the group receiving serum in 3-dimensional culture without FGF2 pretreatment than the serum-free group. For both the serum and serum-free groups that were pretreated with FGF2 in monolayer (683 and 1176 cells $/ \mathrm{mm}^{2}$, respectively), there were more viable cells in the pretreated group than the non- pretreated group (451 and $207 \mathrm{cells} / \mathrm{mm}^{2}$, respectively).

Safranin O staining of proteoglycans in the matrix was present in only 3 groups. (Fig. 3) The TGF $\beta 1$ group without FGF2 pretreatment showed uniform, intense orange staining and $100 \%$ of the total tissue area stained with the safranin O. In contrast, the pretreated TGF $\beta 1$ group showed more diffuse, mottled staining of the extracellular matrix with only $51.8 \%$ of the tissue area showing staining for GAG. The pellet treated with serum without FGF2 pretreatment showed a small thin ring of safranin $\mathrm{O}$ staining (3.0\% of the total area) in the periphery corresponding to matrix seen on $\mathrm{H}$ and $\mathrm{E}$ stained sections.

\section{Capillary Electrophoresis}

Capillary electrophoresis showed type I collagen present consistently in the group receiving TGF $\beta 1$ without FGF2 pretreatment (mean $3.57 \mathrm{ug}$; range $1.02-6.00 \mathrm{ug}$ ). Additionally, this group also had one pellet with detectable type II collagen $(4.5 \mathrm{ug})$. The group pretreated with FGF2 followed by TGF $\beta 1$ had detectible type I collagen in only 2 pellets 2.33 and 4.37 ug. No other group had any detectable type I or type II collagen.

\section{DISCUSSION}

As expected, the overall size of the pellets treated with TGF $\beta 1$ were grossly larger than the other groups, and pretreatment with FGF2 prior to 3-dimensional culture decreased the time to produce the cartilage. This is a desirable effect for clinical scale production of engineered cartilage. However, the groups pretreated with FGF2 had decreased quality and quantity of matrix histologically. This was evident in the pellets treated with serum in addition to those treated with TGF $\beta 1$.

The larger cell number likely contributed to the size of the TGF $\beta 1$ group pretreated with FGF2. This is supported by the 2-fold higher cell count/unit area compared to the TGF $\beta 1$ group without FGF2 pretreatment. Consistently, the extracellular matrix was less prominent and stained less intensely for glycosaminoglycans compared to the non-pretreated TGF $\beta 1$ group despite overall equivalent size and weight. Although this is in contrast to some reports, [21-23] FGF2 has been reported to decrease large proteoglycan deposition and collagen II production in 3-dimensional culture [15,24,31].

This is also apparent in the FGF2 pretreated groups treated with serum or no growth factors in 3-dimensional culture; whereas, the group receiving FGF2 only in pellet culture did not have a large difference in cell count/unit area in the pretreated versus non-treated monolayer culture. Additionally, both groups treated with FGF2 in 3-dimensional cultures had a 3-15 fold higher cell count/ unit area than the other groups.

The higher cell numbers in the FGF2 treated groups may be due to inhibited apoptosis, increased proliferation, or a combination. A similar study found that DNA content decreased over time in pellet culture suggesting cell apoptosis [32]. This supports the supposition that FGF pretreatment inhibits apoptosis instead of promoting proliferation in the pellet cultures. However, the cells were less mature which is consistent with proliferating chondrocytes. Increased proliferation rates are consistent with previous in vitro studies of chondrocytes in monolayer and 3-dimensional studies [15, 31-33]. Ideally, whole pellet cell counts, DNA quantification, or proliferation assays would be needed to confirm this deduction.

Unexpectedly, FGF2 pretreatment in monolayer showed lower matrix production when redifferentiation was induced by TGF $\beta 1$. This is consistent with studies in 3-dimensional cultures which show negative effects of FGF2 on GAG and collagen type II production when used alone [15,24]. However, other studies found using FGF2 in monolayer enhanced the activity of TGF $\beta[22,32]$. It is possible that matrix formation may have surpassed the group without FGF2 treatment in monolayer if cell cultures were maintained for a longer period of time. Additionally, the combination of more than 1 growth factor may enhance the redifferentiation and matrix formation of the chondrocytes over individual growth factors $[32,33]$.

Other studies may have shown enhanced results by using a matrix instead of pellet culture $[17,23]$. The presence of a 3-dimensional matrix has a significant impact on the effect of the growth factor $[34,35]$. One limitation of this study is that it cannot be directly applied to in vitro engineering on a scaffold.

Fibroblastic growth factor 2 also negatively influenced collagen deposition. Only 2 pellets out of 6 showed any collagen using capillary electrophoresis; whereas, TGF $\beta 1$ without FGF2 pretreatment consistently produced detectable amounts of collagen type I. There may also be a dose dependent negative effect of FGF2 at doses of $5 \mathrm{ng} / \mathrm{ml}$ or greater [17]. In this study, $5 \mathrm{ng} / \mathrm{ml}$ of FGF2 was chosen to based on a previous report addressing the amount optimal for mitogenic activity [17]. Potentially, a lower dose would preserve the mitogenic activity without negatively effecting 3dimensional culture. 
Unfortunately, only one pellet in the TGF $\beta 1$ group produced detectable type II collagen. This was in the group without pretreatment. Typically, TGF $\beta 1$ is thought to increase type II and decrease type I collagen production $[10,11,36]$. However, fibrocartilage, the main reparative tissue of cartilage injury in vivo is predominantly type I collagen despite increases in TGF $\beta 1$ with injury in vivo [26]. A study of the phenotypic maintenance of chondrocytes over time found that at $10 \mathrm{ng} / \mathrm{ml}$ of TGF $\beta 1$, type II collagen was upregulated initially but then suppressed after 12 days of treatment [37]. Additionally, TGF $\beta 1$ has also shown decreased levels of collagen type II mRNA in bovine chondrocytes exposed to $25 \mathrm{ng} / \mathrm{ml}$ of TGF $\beta 1$ [24,37]. One study using dedifferentiated chondrocytes showed TGF 1 did not increase type II collagen unless combined with insulin-like growth factor 1, but production of type I collagen was consistent [38]. Combining growth factors or establishing the optimal concentration of TGF $\beta 1$ to use may improve the consistency and quality of the engineered tissue.

Other aspects of the medium may also contribute to the resulting tissue characterization. Despite wide use of dexamethasone in similar studies, there is evidence that it inhibits the upregulation of collagen type II caused by TGF $\beta$ use in vitro [26]. In this study, dexamethasone was used in the serum-free media and may have contributed to the low to absent type II collagen deposition noted. However, the overall size of the pellets were grossly larger than those not receiving TGF $\beta 1$ suggesting that GAG and type I collagen production was minimally affected.

Many of the studies evaluating the effect of TGF $\beta 1$ on collagen production have utilized mRNA techniques or semi-quantification based on immunohistochemistry $[10,11$, $24,36,39]$. Quantification using mRNA has the obvious disadvantage of identifying what might be produced versus the actual matrix produced, and immunohistochemical techniques are only semi-quantitative. More recently, an ELISA for human, bovine, and mouse collagen type II has been introduced, but it has not been validated for canine collagen. Additionally, the ELISA may require pooling of samples to meet the minimum detectable amount of collagen type II. In this study, we used capillary electrophoresis to quantify the amount of type I and II produced.

Capillary electrophoresis is a method of detecting extremely small amounts of protein [30]. We used known amounts of purified type I and II collagen to determine if our methodology was sound. The standard curves produced correlated highly $\left(\mathrm{R}^{2}=0.95\right)$ with known quantities of the collagens. Despite this assurance, it is possible that small quantities of type II collagen were present beneath the detectable threshold. Limitations of the technique can cause underestimation of type II collagen including incomplete cyanogen bromide digestion and decreased relative sensitivity of type II compared to type I collagen. The minimum detection limit was not determined in this study; however, the known lowest amount accurately detected in the standard curve was $0.89 \mathrm{ng}$. This is less than typically detected by the commercially available type II collagen ELISA kits [40].

Although these results are not entirely consistent with the literature, studies are extremely difficult to compare. Similarities between papers include cell type, harvest method, basic techniques such as pipetting and cell passage, and the physical monolayer environment. Additionally, the use of pellet culture for 3-dimensional studies is common. However, medium additives, individual characteristics, and species differences cause variation in outcome. In addition, there is large variation between individuals [17]. Although comparing the effects of growth factors within a species would arguably be more consistent, studies using canine chondrocyte cultures are uncommon.

In this study, only one dog was used to harvest chondrocytes. Others have used this methodology [17]. This is advantageous in limiting the variation between dogs. Using one dog also eliminates hidden bias in pooled cell populations where one dog may still have a predominant influence over results. However, the results cannot be generalized to the entire population of dogs.

Under the culture conditions described here, TGF $\beta 1$ increased the size and GAG content of matrix produced by chondrocytes. Additionally, FGF2 in monolayer was mitogenic, but negatively influenced matrix formation in 3dimensions. FGF2 and TGF $\beta 1$, individually or in succession, did not promote collagen type II deposition.

\section{ACKNOWLEDGEMENTS}

Capillary electrophoresis was run by The Protein Facility of the Iowa State University Office of Biotechnology. Image analysis was performed with the aid of the Image Analysis Facility of the Iowa State University Office of Biotechnology.

\section{REFERENCES}

[1] Lawrence RC, Helmick CG, Arnett FC, et al. Estimates of the prevalence of arthritis and selected musculoskeletal disorders in the United States. Arthritis Rheum 1998: 41; 788-99.

[2] Ge Z, Hu Y, Heng BC, et al. Osteoarthritis and therapy. Arthritis Rheum 2006; 55(3): 493-500.

[3] Proprietary market research, 1996. Veterinary sample size: 200. Data on file, Pfizer Animal Health.

[4] Proprietary market research, 1996, Veterinary sample size: 265 Data on file, Pfizer Animal Health.

[5] Sams AE, Nixon AJ. Chondrocyte-laden collagen scaffolds for resurfacing extensive articular cartilage defects. Osteoarthritis Cartilage $1995 ; 3:$ 47-59.

[6] Rahman MS, Tsuchiya T. Enhancement of chondrogenic differentiation of human articular chondrocytes by biodegradable polymers. Tissue Eng 2001: 7; 781-90.

[7] Caplan AI. Mesenchymal stem cells: Cell-based reconstructive therapy in orthopedics. Tissue Eng 2005; 11: 1198-211.

[8] Darling EM, Athansiou KA. Growth factor impact on articular cartilage subpopulations. Cell Tissue Res 2005; 322: 463-73.

[9] Lee JE, Kim KE, Kwon IC, et al. Effects of the controlled-release TGF- $\beta 1$ from chitosan microspheres on chondrocytes cultured in collagen/chitosan/glycosaminoglycan scaffold. Biomaterials 2004; 25: 4163-73.

[10] Weisser J, Rahfoth B, Timmermann A, Aigner T, Bräuer R, von der Mark K. Role of growth factors in rabbit articular cartilage repair by chondrocytes in agarose. Osteoarthritis Cartilage 2001; 9: S48-54.

[11] Moretti M, Wendt D, Dickinson SC, et al. Effects of in vitro preculture on in vivo development of human engineered cartilage in an ectopic model. Tissue Eng 2005; 11(9-10): 1421-8.

[12] Park K, Huang J, Azar F, et al. Scaffold free, engineered porcine cartilage construct for cartilage defect repair - in vitro and in vivo study. Artif Organs 2006; 30: 586-96.

[13] Barbero A, Palumberi V, Wagner B, Sader R, Grote MJ, Martin I. Experimental and mathematical study of the influence of growth factors on the growth kinetics of adult human articular chondrocytes. J Cell Physiol 2005; 204: 830-38. 
[14] Mandl EW, Jahr H, Koevoet JLM, et al. FGF2 in serum-free medium is a potent mitogen and reduces dedifferentiation of human ear chondrocytes in monolayer culture. Matrix Biol 2004; 23: 23141.

[15] Pei M, Seidel J, Vunjak-Novakovic G, Freed LE. Growth factors for sequential cellular de- and re-differentiation in tissue engineering. Biochem Biophys Res Commun 2002; 294: 149-54.

[16] Martin I, Suetterlin R, Baschong W, Heberer M, VunjakNovakovic G, Freed LE. Enhanced cartilage tissue engineering by sequential exposure of chondrocytes to FGF2 during 2D expansion and BMP2 during 3D cultivation. J Cell Biochem 2001; 83: 121-8.

[17] Veileux N, Spector M. Effects of FGF-2 and IGF-1 on adult canine articular chondrocytes in type II collagen-glycosaminoglycan scaffolds in vitro. Osteoarthritis Cartilage 2005; 13: 278-86.

[18] Fortier LA, Nixon AJ, Mohammed HO, Lust G. Altered biological activity of equine chondrocytes cultured in a three-dimensional fibrin matrix and supplemented with transforming growth factor beta-1. Am J Vet Res 1997; 58(1): 66-70.

[19] Giannoni P, Pagano A, Maggi E, et al. Autologous chondrocyte implantation (ACI) for aged patients: development of the proper cell expansion conditions for possible therapeutic applications. Osteoarthritis Cartilage 2005; 13(7): 589-600.

[20] Kawamura K, Chu CR, Sobajima S, et al. Adenoviral -mediated transfer of TGF- $\beta 1$ but not IGF-1 induces chondrogenic differentiation of human mesenchymal stem cell in pellet cultures. Exper Hemat 2005; 33: 865-72.

[21] Mastrogiacomo M, Cancedda R, Quarto R. Effect of different growth factors on the chondrogenic potential of human bone marrow stromal cells. Osteoarthritis Cartilage 2001; 9: S36-40.

[22] Solchaga LA, Penick K, Porter JD, Goldberg VM, Caplan AI, Welter JF. FGF-2 enhances the mitotic and chondrogenic potentials of human adult bone marrow-derived mesenchymal stem cells. J Cell Physiol 2005; 203: 398-409.

[23] Miot S, Scandiucci de Freitas P, Wirz D, et al. Cartilage tissue engineering by expanded goat articular chondrocytes. J Orthop Res 2006; 24(5): 1078-85.

[24] Jenniskens YM, Koevoet W, de Bart W, et al. Biochemical and functional modulation of the collagen network by IGF1, TGF $\beta 2$, and FGF2. Osteoarthritis Cartilage 2006; 14: 1136-46.

[25] Quarto R, Campanile G, Cancedda R, Dozin B. Modulation of commitment, proliferation, and differentiation of chondrogenic cells in defined culture medium. Endocrinology 1997; 138(11): 4966-76.

[26] Grimaud E, Heymann D, Redini F. Recent advances in TGF-beta effects on chondrocyte metabolism. Potential therapeutic roles of TGF-beta in cartilage disorders. Cytokine Growth Factor Rev 2002; (3): 241-57.
[27] Nixon AJ, Lillich JT, Burton-Wurster N, Lust G, Mohammed HO. Differentiated cellular function in fetal chondrocytes cultured with insulin-like growth factor-I and transforming growth factor-beta. J Orthop Res 1998; 16(5): 531-41.

[28] Glowacki J, Yates KE, MacLean R, Mizuno S. In vitro engineering of cartilage: effects of serum substitutes, TGF- $\beta$, and IL- $1 \alpha$. Orthod Craniofacial Res 2005; 8: 200-8.

[29] O'Driscoll SW, Keeley FW, Salter RB. The chondrogenic potential of free autogenous periosteal grafts for biological resurfacing of major full-thickness defects in joint surfaces under the influence of continuous passive motion. An experimental investigation in the rabbit. J Bone Joint Surg 1986; 68A: 1017-35.

[30] Chalmers M, Huckle J, Cotton NJ. Development of a capillary electrophoresis method for the characterization of collagens in cartilage tissue. J Chromat Sci 1999; 37: 443-7.

[31] Wroblewski J, Edwall-Arvidsson C. Inhibitory effects of basic fibroblast growth factor on chondrocyte differentiation. J Bone Miner Res 1995; 10(5): 735-42.

[32] Yang IH, Kim SH, Kim YH, Sun HJ, Kim SJ, Lee JW. Comparison of phenotypic characterization between "alginate bead" and "pellet" culture systems as chondrogenic differentiation models for human mesenchymal stem cells. Yonsei Med J 2004; 45(5): 891-900.

[33] van der Kraan PM, Buma P, van Kuppevelt T, van den Berg WB. Interaction of chondrocytes, extracellular matrix and growth factors: relevance for articular cartilage tissue engineering. Osteoarthritis Cartilage 2002; 10(8): 631-7.

[34] Qi WN, Scully SP. Type II collagen modulates the composition of extracellular matrix synthesized by articular chondrocytes. J Orthop Res 2003; 21(2): 282-9.

[35] Stevens MM, George JH. Exploring and engineering the cell surface interface. Science 2005; 310: 1135-8

[36] Worster AA, Nixon AJ, Bower-Toland BD, Williams J. Effect of transforming growth factor $\beta 1$ on chondrogenic differentiation of cultured equine mesenchymal stem cells. Am J Vet Res 2000; 61: 1003-10.

[37] Han F, Adams CS, Tao Z, et al. Transforming growth factor-beta1 (TGF-beta1) regulates ATDC5 chondrogenic differentiation and fibronectin isoform expression. J Cell Biochem 2005; 95(4): 750-62.

[38] Yaeger PC, Masi TL, de Ortiz JL, Binette F, Tubo R, McPherson JM. Synergistic action of transforming growth factor-beta and insulin-like growth factor-I induces expression of type II collagen and aggrecan genes in adult human articular chondrocytes. Exp Cell Res 1997; 237(2): 318-25.

[39] Darling EM, Athansiou KA. Growth factor impact on articular cartilage subpopulations Cell Tissue Res 2005; 322: 463-73.

[40] Collagen type II ELISA package insert. MDBiosciences CII96. Accessed online www.mdbiosciences.com/CII96_Insert.pdf 4/1/08.

Received: April 3, 2008

Revised: May 16, 2008

Accepted: May 16, 2008

(c) Gordon-Evans et al.; Licensee Bentham Open

This is an open access article distributed under the terms of the Creative Commons Attribution License (http://creativecommons.org/licenses/by/2.5/), which permits unrestrictive use, distribution, and reproduction in any medium, provided the original work is properly cited. 